\section{Analysis of information on food chain in Europe and Piedmont region, Italy}

\author{
Daniele Pattono, Barbara Bertolina, \\ Maria Teresa Bottero, Francesco Chiesa, \\ Tiziana Civera \\ Dipartimento di Scienze Veterinarie, \\ Università degli Studi di Torino, \\ Grugliasco (TO), Italy
}

\begin{abstract}
Food chain information (FCI) is an innovation of the new European regulation. Its purpose is to enhance the concept of food security. FCI includes specifications such as: health status, information on treatments and diseases, analytical reports on control plans, zoonoses or environmental contaminants, production performance, etc. The aim of this article is to compare the different European guidelines and analyse the situation in Piedmont in order to assess potential problems and propose solutions. European guidelines are similar one another, but they have been tailored to the epidemiological situations of each state. Except for Spain and Germany, FCI models are different for each species and the poultry sector is the most detailed. Unfortunately, Italy has not provided guidelines yet, and this has generated considerable differences. Overall, the number of FCI models with incomplete information is the largest group compared to the models not completed for each entry. The main deficiencies are related to pharmacological treatments. The health status of the farm is listed consistently regarding the compulsory eradication plans, but other national voluntary or accreditation plans are rarely mentioned. The situation is similar in other European countries. In conclusion, FCI is an effective tool if applied with consistency and reason. Only in this way the collection of data will be effective and representative of the food chain
\end{abstract}

\section{Introduction}

Food chain information (FCI) is one of the innovations introduced by the hygiene package to enhance the concept of food security and ensure welfare and animal health. Food chain information can be used by the operator of the slaughterhouse within the HACCP plan in order to organise the slaughtering and by the official veterinarian to take decisions on the carcass. Information should cover what follows (European Commission, 2004): i) status of provenance or the regional animal health status; veterinary medicinal products or other treatments administered within a relevant period and with a withdrawal period $>0$, together with their dates of administration and withdrawal periods; ii) occurrence of diseases that may affect the safety of the meat; iii) the results, if they are relevant to the public health, of any analysis carried out on samples taken from the animals or other samples taken to diagnose diseases that may affect the safety of the meat, including samples taken in a framework of the monitoring and control of zoonoses and residues; iv) relevant reports about previous ante- and post-mortem inspections of animals from the same holding of provenience, including reports from the official veterinarian production data when they may indicate the presence of diseases; v) name and address of the private veterinarian normally attending the holding of provenience.

FCI must be provided to the slaughterhouse operators at least $24 \mathrm{~h}$ before the arrival of the animals. It is also possible to send FCI simultaneously in the following cases: for pigs, poultry or farmed game that have passed the antemortem inspection at the farm and are accompanied by a veterinary certificate declaring the animals as healthy; for slaughtering of domestic solipeds or other animals subject to emergency slaughter if accompanied by a veterinary certificate attesting the successful antemortem inspection; for animals that have not been sent directly from the holding of provenance to the slaughterhouse.

Within the Council Regulation (EC) $\mathrm{n}$. 2076/2005 (European Commission, 2005) there is another exception to Regulation (EC) n. 853/2004 (European Commission, 2004), which provides for the simultaneous transmission of FCI and animals regardless of species, subject to agreements between food business operator (FBO) and the official veterinary. If the veterinary decides for the slaughtering, even in the absence of $\mathrm{FCI}$, the document must be provided within $24 \mathrm{~h}$, otherwise the entire carcass will be destroyed. Several EU member states drafted guidelines for the correct application of the document. Unfortunately in Italy only few regions did it.

The aim of the present work is to compare the different European guidelines and to analyse the situation in Piedmont after few years of the entry into force of this provision in order to assess the presence of potential problems and propose solutions.

\section{Materials and Methods}

Guidelines of several EU nations have been considered. In particular we analysed the guidelines of: France, United Kingdom,
Correspondence: Maria Teresa Bottero, Dipartimento di Scienze Veterinarie, Università degli Studi di Torino, Largo Paolo Braccini 2, 10095 Grugliasco (T0), Italy.

Tel. +39.011.6709214 - Fax: +39.011.6709224.

E-mail: mariateresa.bottero@unito.it

Key words: FCI, Slaugthtering, Food hygiene regulation.

Received for publication: 14 May 2013.

Accepted for publication: 22 January 2014.

This work is licensed under a Creative Commons Attribution 3.0 License (by-nc 3.0).

(C) Copyright D. Pattono et al., 2014

Licensee PAGEPress, Italy

Italian Journal of Food Safety 2014; 3:1721

doi:10.4081/ijfs.2014.1721

Belgium, The Netherlands, Spain and Germany (AFFSA, 2008; Spanish Government, 2009; AFSCA, 2009; PVE, 2014). For each country we evaluated the guidelines and compared information contained within the FCI for the different animal species. In order to analyse the situation in the Piedmont year we collected for one year and compared the FCI in 11 slaughterhouses differing among them for capacity and slaughtered species (cattle, pigs, small ruminants, poultry, rabbits and horses). The FCI models were classified as: FCI negative (compiled form with one or more items not completed); FCI absent (module of not completed for any item); FCI positive (compiled for each item). In the end we analysed which information was lacking in the FCI negative class.

\section{Results and Discussion}

The different guidelines proposed in the European Union, despite being similar in many parts, have undergone adaptations depending on the epidemiological situation of each state. All these adaptations have occurred as the results of inspections carried out by the central and/or the Food Veterinary Office (FV0). In particular, these adaptations took into consideration the diseases occurring in each country. The forms varied from very detailed on specific diseases to forms in which only symptoms are requested (AFFSA, 2008).

Considering the animal specificity of the models, the majority of the examined countries - Italy included - have different models for each species. Only Spain and Germany have a single model regarding all species (Spanish Government, 2009; German Republic, 2004). In general, the FCI model of the poultry industry is the most detailed in all countries. 
Other differences concern the transmission of data. Most of the countries have paper forms; but Holland, uses computerised systems for small ruminants, for example.

The FCI model is sent the day before slaughtering with few exceptions. In France FCI for poultry and rabbits is sent $48 \mathrm{~h}$ before slaughtering. In Holland for sheep, goats and cattle it is possible to send FCI simultaneously with the animals if few animals are sent for the slaughtering. A common finding is the fact that the FCI models are collected by simple questions with direct answer (yes/no) and in the forms blanks for any additional information are provided.

Italy, unlike other European countries, has not provided the guidelines. Every region has its own modules. This situation results in large discrepancies such as: undifferentiated modules or modules differentiated by species, modules integrated or non-integrated to other mandatory documents (e.g. Mod. IV), modules with space or without space for additional data (symptoms, pharmaceutical treatments). In general, almost all of the Piedmont slaughterhouses considered do not require the document $24 \mathrm{~h}$ before the arrival of the animals. For all the species considered, the number of FCI forms classified as negative is the most representative group (from 78.89 to $99.1 \%$ ) and the models classified as positive are the smallest group (from 0 to $7.14 \%$ ). The absent group ranges from 0.88 to $11.21 \%$. An important consideration must be ruled out related to the slaughtering capacity: the less the number of slaughtered animals, the more attention is paid by the veterinary service to check the forms.

In addition to these general considerations our analysis highlighted some critical issues related to individual species.

For cattle in the category FCI negative, the missing data concerns, mainly, forms where pathologies were signaled but symptoms were not reported. In particular, those animals were sent for an emergency slaughtering or were accompanied by health certificates compiled by the private veterinarian. For the category FCI absent the high percentage (8.25\%) recorded in a slaughterhouse was due to agreements between farmers and the FBO as a part of the supplier's accreditation process. It is clear that this is not just an arbitrary interpretation of the concept of the FCI, but also improper extension of the accreditation process.

Another finding for cattle is that the FCI is often considered data related to the farm and not the animals sent to the slaughterhouse. For this reason sometimes cattle from the same farm had more models $\mathrm{n}$. IV and only one FCI model. Considering pigs, a peculiarity is due to the fact that some slaughterhouses export to Australia, Russian Federation and
China. For this slaughter plants, the information contained in the FCI module gives additional health information being a mandatory request of the importing nation.

Considering the equine sector, a critical common point is the fact that many documents are written in the language of the country of origin only. As for small ruminants, the lack of specific models has affected the collection of information. Furthermore, the high percentage of parasitosis often found in post-mortem are not linked to an appropriate record neither of treatments nor of symptoms on the FCI form. For poultry the possibility to perform ante-mortem inspection in the holding of provenance makes compulsory to fill out a health certificate in addition to the accompanying document. Only in poultry slaughterhouses the FCI form is always sent to the slaughterhouse $24 \mathrm{~h}$ before the arrival of the animals. This agreement with the veterinary service enables the FBO to avoid the compilation of the health certificate representing a charge for him. In rabbits slaughtering the form was sent $24 \mathrm{~h}$ before the arrival of the animals due to the higher percentage of drug treatments.

In the end, our analisys stressed out a certain number of criticities common for all the species considered. The FCI negative is due mostly to the lack of information about symptoms even in the presence of health certificates and drug treatments. Sometimes drug treatments are completely omitted on FCI modules and on model $n$. IV or sometimes declared on the model n. IV and absent on FCI modules. Another situation was observed regarding the health status. The information of livestock is almost always reported in reference to compulsory eradication plans for domestic cattle, pigs and small ruminants, while data are never reported to voluntary schemes or specific accreditation programmes.

Finally, we infer how in our country the real benefit derived from FCI in terms of better health quality of food as a consequence of the uniformity and timely completion of this model is not yet fully understood (Franchini, 2004). However, these findings are completely in line with what has been shown by the audit of the FVO in other European countries, such as Ireland, Lithuania and Cyprus (European Commission, 2011, 2012a, 2012b). Given the large differences emerged, in our opinion it is essential to standardise the system by the aid of training courses and of new official FCI forms, with guidelines for the compilation (Appendix).

\section{Conclusions}

The EU reiterates the importance of increasing the level of food safety through the collection and transmission of information along the entire food chain. FCI is a reliable tool to achieve it. From the data collected in this investigation the importance of FCI seems not to be perceived by the FBO and also by the public veterinary service, which is often limited to assess the presence of the form, without checking its content. We believe that the issue of guidelines by the State-Regions Conference could in Italy, like in other EU countries, give effectively increase the veterinary checks at slaughter and therefore favour the safety of the meat.

\section{References}

AFFSA, 2008. Available from: http://www.anses.fr/Documents/SANT2008 sa0240.pdf

AFSCA, 2009. Available from: http://www. favv.be/productionanimale/animaux/ica/se cteuravicole/_documents/2011-0120_ICAinstructionsremplirformula iregeneral_FR.pdf

European Commission, 2004. Regulation of the European Parliament and of the Council of 29 April 2004 laying down specific hygiene rules for food of animal origin, 853/2004/EC. In: Official Journal, L 139, $30 / 04 / 2004$.

European Commission, 2005. Regulation of the European Parliament laying down transitional arrangements for the implementation of Regulations (EC) No 853/2004, (EC) No 854/2004 and (EC) No 882/2004 of the European Parliament and of the Council and amending Regulations (EC) No 853/2004 and (EC) No 854/2004, 2076/2005/CE. In: Official Journal, L 338, $5 / 12 / 2005$.

European Commission, 2011. Final report of an audit carried out in Ireland from 17 to 28 October 2011 in order to evaluate the follow-up action taken by the competent authorities with regard to official controls related to the safety of food of animal origin, in particular meat, milk and their products. Available from: http://ec.europa.eu/ food/fvo/act_getPDF.cfm?PDF_ID=9581

European Commission, 2012a. Final report of an audit carried out in Cyprus from 23 January to 02 February 2012 in order to evaluate the follow-up action taken by the competent authorities with regard to official controls related to the safety of food of animal origin, in particular meat, milk and their products. Available from: http://ec.europa.eu/food/fvo/act_getPDF.cf m?PDF_ID=9709

European Commission, 2012b. Final report of an audit carried out in Lithuania from 31 
January to 10 February 2012 in order to evaluate the follow-up action taken by the competent authorities with regard to official controls related to the safety of food of animal origin, in particular meat, milk and their products. Available from: http://ec. europa.eu/food/fvo/act_getPDF.cfm?PDF_I $\mathrm{D}=9594$

Franchini L, 2004. Convegno del Centro Informazioni Carni Olandesi al Sial 2004.
Eurocarni 12:91.

FSA, 2008. Available from: http://www.food.gov. uk/multimedia/pdfs/fcipigletterscot071113 .pdf

German Republic, 2004. Available from: http://www.landkreis-ludwigsburg.de /fileadmin/kreis-lb.de/pdf-dateien/buergerinfo/gesundheit/veterinaerangelegenheiten/lebensmittelueberwachung/fb_lebensmittelketteninformation.pdf
PVE, 2014. Available from: http://www.pve .nl/pve? waxtrapp=qcbHsHsuOnbPTEcBbBI L\&context=nfMsHsuOnbPTEC

Spanish Government, 2009. Available from: http://www.aragon.es/estaticos/ImportFiles /12/docs/Areas/Ganaderia/Informacion_Ca dena_Alimentaria/INSTRUCCIONES_CU MPLIMENTACION_INFORMACION_CADE NA_ALIMENTARIA_SACRIFICIO.pdf 